\title{
INVESTIMENTO NA CAPACIDADE DE PRODUÇÃO EM UM AMBIENTE SIMULADO
}

\section{INVESTMENT IN THE CAPACITY OF PRODUCTION IN A SIMULATE ENVIRONMENT}

\author{
Bruno Hartmut Kopittke, Dr. \\ Universidade Federal de Santa Catarina \\ Programa de Pós Graduação em Engenharia de Produção \\ Caixa Postal 476 - CEP 88010-970 Trindade - Florianópolis - SC \\ bruno@deps.ufsc.br
}

(48) $331-7047$

\begin{abstract}
Julio Cezar Mairesse Siluk, M. Eng.
Universidade Federal de Santa Catarina

Programa de Pós Graduação em Engenharia de Produção

Caixa Postal 476 - CEP 88010-970 Trindade - Florianópolis - SC

jsiluk@unifra.br

(48) $331-7047$

Juliano Zaffalon Gerber, M. Eng.

Universidade Federal de Santa Catarina

Programa de Pós Graduação em Engenharia de Produção

Caixa Postal 476 - CEP 88010-970 Trindade - Florianópolis - SC

juliano@deps.ufsc.br
\end{abstract}

(48) $331-7047$

\section{RESUMO}

Com o objetivo de contribuir com a teoria sobre avaliação de desempenho, gestão estratégica e jogos de empresas, este estudo apresenta uma abordagem de avaliação e inovação do jogo de empresas GI-Logística. Inicialmente, faz-se uma apresentação do jogo de empresas, indicando as suas principais características, objetivos e condução dos elementos para tomada de decisão, com foco nos investimentos na capacidade produtiva. A 
segunda seção desse estudo aborda a metodologia de gestão e avaliação de desempenho do Balanced Scorecard, com ênfase nos processos de operações. A ferramenta Balanced Scorecard será descrita para ser utilizada como baliza para as atualizações no jogo de empresas GI-Logística. Finalmente, são sugeridas alterações no jogo de empresas GILogística, bem como as devidas alterações no seu material didático de apoio.

Palavras-Chave: Jogos de empresas, Balanced Scorecard, Capacidade de produção.

\begin{abstract}
With the objective of contributing with the theory about performance, strategic administration and business games, this study presents an evaluation and innovation approach of the GILogística business games. Initially, it is made a presentation of the business games, indicating your characteristic principal, objectives and conduction of the elements for take of decision with focus in the investments in the working production. The second section approaches the administration methodology and evaluation of performance of Balanced Scorecard, with emphasis in the processes of operations. The tool Balanced Scorecard will be described to be used as mark for the updatings in the GI-Logística business games. Finally, they are suggested alterations in the GI-Logistica business games, as well as the due alterations in your didactic material of support.
\end{abstract}

Key words: Business games, Balanced Scorecard, Capacity for production.

\title{
1. INTRODUÇÃO
}

A evolução dos sistemas administrativos e da informática ocasiona uma necessidade constante de manutenção e atualização dos jogos empresariais. Este artigo ilustra a atualização do jogo de empresas GI-Logística, desenvolvido no Laboratório de Jogos de Empresas da Universidade Federal de Santa Catarina, UFSC e apresenta a proposta de definir regras e parâmetros mais realísticos aos investimentos no sistema produtivo das empresas simuladas, aproximando ainda mais o cenário apresentado neste jogo à realidade empresarial.

Importante fonte de idéias, os estudos desenvolvidos na disciplina Gestão de Negócios, com Aplicação de Jogos de Empresas, ministrada no Programa de Pós-Graduação 
em Engenharia de Produção, da UFSC, contribuem sobremaneira às inovações realizadas nos jogos de empresas do Laboratório de Jogos de Empresas, LJE.

Ishikawa (2004) identifica que, para evitar a modelagem de questões complexas que resultem na adoção de estratégias "aleatórias", deve-se balancear a complexidade de processamento do jogo. Dentre as proposições apresentadas por Ishikawa, é dada especial atenção à estratégia de bens de capital (imobilizado), um dos elementos foco desde estudo. Já Siluk (2004) avalia o jogo de empresas GI-Logística, da perspectiva dos processos internos, utilizando-se para tal o Balanced Scorecard. Dessa forma, centra-se nos processos de operações e procura verificar as relações de causa e efeito dos objetivos das empresas nesta perspectiva. Nesse sentido, este trabalho, com a contribuição dos estudos de Siluk, analisa as relações de causa e efeito da decisão de compra de equipamentos.

Como resultados são esperados indicadores às atualizações no modelo do jogo de empresas GI-Logística, no que se refere à gestão do imobilizado. Os textos apresentados neste trabalho podem e devem ser utilizados na atualização dos manuais do jogador e do animador, bem como na revisão dos jornais.

Dessa forma, este artigo apresenta o jogo de empresas GI-Logística, a metodologia Balanced Scorecard, sob a perspectiva dos processos internos e sua relação com o GILogística, as propostas de ajustes e as conclusões do estudo.

\section{O JOGO DE EMPRESAS GI-LOGÍSTICA}

O GI-Logística é um jogo que simula a vida empresarial por meio de um modelo que considera as principais variáveis do ambiente industrial, operando com quatro diretorias: marketing, produção, financeira e geral. Para cada uma delas existe um conjunto de variáveis que deve ser analisado para gerar as decisões referentes a um determinado período, que no caso do presente jogo, é trimestral. O objetivo das empresas é obter o melhor desempenho, o qual será medido, principalmente, pelo lucro acumulado, e pelas avaliações da produção, do marketing e do financeiro (KOPITTKE, 2004). A utilização do Balanced Scorecard no jogo visa a apresentar uma visão mais abrangente da avaliação das empresas virtuais, bem como, avaliar o próprio Balanced Scorecard, como instrumento de gestão.

Desse modo, o jogo opera com um único tipo de produto sendo fabricado e vendido pelas empresas, não apresentando diferenças na qualidade, nem na sua composição. O produto consiste em um bem de consumo durável, representado por um eletrodoméstico. O número de funcionários e o valor do investimento em imobilizado são os fatores limitativos da 
capacidade de produção das empresas. As empresas atuam comercialmente em um mercado dividido em regiões, sendo uma delas, a região que desenvolve o papel de mercado externo, e as demais, que equivalem a uma região para cada equipe presente na simulação. As empresas iniciam o jogo partindo de uma mesma situação patrimonial. Após o estudo das regras, das definições dos papéis a serem executados pelos participantes, da análise dos relatórios gerenciais iniciais e das informações contidas no jornal, dá-se o processo de tomada de decisões (KOPITTKE, 2004).

No GI-Logística, assim como em qualquer empresa, os bens destinados à manutenção das atividades de produção são tratados como Imobilizado. Outra característica do jogo, comum a qualquer empresa, é a depreciação do imobilizado que corresponde à diminuição parcelada do valor dos equipamentos, resultante do desgaste pelo uso, da ação da natureza ou de obsolescência normal.

Os participantes do jogo recebem empresas com características semelhantes. Cada empresa inicia com imobilizado equivalente a um investimento de 500.000 unidades monetárias e, após operar um período, as máquinas são depreciadas, em $2.5 \%$, em função de seu desgaste natural. Para manter a capacidade de produção deve-se cobrir os custos da depreciação, e para aumentar a capacidade produtiva, o investimento deve ser superior ao custo de depreciação, sendo que, em ambos os casos, com um período de antecedência. Todo imobilizado que as empresas possuem tem um rendimento que determina a quantidade de insumos que são necessários para a produção de um produto, sendo este rendimento responsável direto pelo custo de produção, gerenciamento de compras e estoque de insumos, itens de suma importância para a otimização dos recursos das empresas, sua competitividade e rentabilidade (DETTMER 2001).

A importância dos investimentos no jogo deve refletir o peso dessas questões no mundo real. Segundo Albuquerque (1987), as decisões de investimentos são consideradas as mais importantes por afetarem todos os aspectos do negócio, dentro de uma organização empresarial, qualquer que seja seu ramo de atividade. Nesse sentido, foram detectadas relações de causa e efeito da decisão de compra de equipamento do jogo de empresas GILogística, sob a perspectiva dos processos internos do Balanced Scorecard, próximo tópico que será apresentado.

\section{O BALANCED SCORECARD}


O Balanced Scorecard traduz a missão e a estratégia de uma empresa em objetivos operacionais e medidas de desempenho para quatro perspectivas diferentes: a perspectiva financeira, a perspectiva do cliente, a perspectiva do processo interno do negócio e a perspectiva de aprendizagem e crescimento. A perspectiva financeira descreve as conseqüências econômicas de ações tomadas nas outras três perspectivas. A perspectiva do cliente define os segmentos de clientes e de mercado no qual a empresa irá competir. A perspectiva do processo interno do negócio descreve os processos internos necessários para fornecer valor aos clientes e aos proprietários. Finalmente, a perspectiva de aprendizagem e crescimento define as competências que uma empresa precisa para criar crescimento e melhorias de longo prazo. Os indicadores estratégicos podem ser vistos não como medidas de desempenho nas quatro perspectivas independentemente, mas como uma série de relações de causa e efeito entre os objetivos, nas quatro perspectivas do Balanced Scorecard (KAPLAN e NORTON, 1997).

\subsection{A perspectiva do processo interno}

Processos são os meios para a criação de valor ao cliente e ao acionista. Assim, a perspectiva do processo engloba a identificação dos processos necessários para atingir os objetivos financeiros e do cliente. Para fornecer a estrutura necessária para essa perspectiva, uma cadeia de valores de processo é definida. A cadeia de valores do processo é composta por três processos: o processo de inovação, o processo de operações e o processo de serviços pósvendas. O processo de inovação antecipa as necessidades emergentes e em potencial de clientes e cria novos produtos e serviços para satisfazer essas necessidades. O processo de operações produz e entrega produtos e serviços existentes aos clientes. Ele começa com um pedido do cliente e termina com a entrega do produto ou serviço. O processo de serviços pósvendas fornece serviços críticos e reativos aos clientes depois que o produto ou o serviço foi entregue (KAPLAN e NORTON, 1997). Portanto, para melhor alcançar os objetivos deste estudo, tratar-se-á apenas sobre os Processos de operações.

\subsubsection{Processos de operações}

Os aprimoramentos nos processos operacionais quase sempre geram resultados em curto prazo, por meio de reduções de custos e melhorias de qualidade. Os processos de operações são os processos básicos do dia-a-dia, através dos quais as empresas produzem os atuais produtos e serviços e os entregam aos clientes. Os processos operacionais de empresas industriais abrangem as atividades de adquirir materiais de fornecedores, converter materiais 
em produtos acabados, distribuir produtos acabados aos clientes e gerenciar o risco (KAPLAN e NORTON, 2001).

Entre os objetivos e indicadores para que os processos sejam mais eficientes na produção de bens e serviços, incluem-se os seguintes, conforme se apresentam no Quadro 1:

\begin{tabular}{|l|l|}
\hline Objetivos & Indicadores \\
\hline$\bullet$ Redução de custos de produção & $\bullet$ Custo por unidade de produção \\
\cline { 2 - 2 } & $\begin{array}{l}\bullet \text { Despesa com vendas e marketing como } \\
\text { porcentagem dos custos totais }\end{array}$ \\
\hline $\begin{array}{l}\text { - Melhor utilização do ativo } \\
\text { imobilizado }\end{array}$ & $\bullet$ Capacidade utilizada \\
\hline $\begin{array}{l}\text { Melhorar a eficiência do capital de } \\
\text { giro }\end{array}$ & $\bullet$ Prazo médio de contas a receber \\
\cline { 2 - 2 } & $\bullet$ Ciclo financeiro ou de caixa \\
\hline
\end{tabular}

Quadro 1- Objetivos estratégicos e seus indicadores.

Fonte: (Adaptado de KAPLAN e NORTON, 2004).

Para transformar o valor potencial dos ativos intangíveis em valor tangível, necessitase de processos internos, como projeto, produção, entrega e serviços aos clientes. Se os processos internos não forem direcionados no sentido da proposição de valor para os clientes ou de melhorias financeiras, o valor potencial das competências dos empregados e dos ativos intangíveis não será concretizado.

\section{AVALIAÇÃO DO JOGO DE EMPRESAS SOB A ÓTICA Balanced Scorecard}

A avaliação do jogo de empresas GI-Logística, sob a perspectiva dos processos internos do Balanced Scorecard, centrou-se nos processos de operações, procurando verificar as relações de causa e efeito dos objetivos desta perspectiva, com a tomada de decisão referente ao investimento na capacidade de produção (Imobilizado). O investimento na capacidade de produção é um fator estratégico no GI-Logística, pois gera benefícios.

Quanto aos objetivos de capacidade produtiva, cabe à empresa controlá-la, equilibrando a capacidade dos equipamentos e a capacidade da mão-de-obra e determinando o ritmo de produção. A empresa deve calcular a necessidade de insumos para o período e posteriormente tomar decisão de comprá-los. Estas decisões conduzem a uma melhor 
utilização do Ativo imobilizado e melhora a estrutura de custos, bem como a eficiência do capital de giro.

O gerenciamento do risco deve garantir que a empresa tenha caixa disponível para efetuar investimentos que aumentem o valor. A estratégia adequada de gerenciamento de riscos garante que a empresa tenha dinheiro na hora de aproveitar as oportunidades de investimento. A determinação do grau de endividamento adequado influencia o risco. Nesse sentido, as empresas que optam pela utilização de empréstimos de capital de giro estão mais sujeitas a terem dificuldades financeiras, principalmente nos períodos de retração da demanda. Por outro lado, as empresas com alto nível de endividamento, empréstimos de longo prazo para aquisição de imobilizado, quando lucrativas, podem ter um fluxo de caixa equilibrado, melhorando a eficiência do capital de giro. A determinação do prazo de pagamento que será concedido aos clientes deve evitar flutuações no fluxo de caixa.

O Quadro 2, Objetivos Estratégicos, Balanced Scorecard e Plano de Ação, ilustra as principais decisões tomadas pelas empresas, no que se refere à Capacidade Produtiva, aos indicadores da perspectiva Processos Internos e aos objetivos estratégicos das empresas.

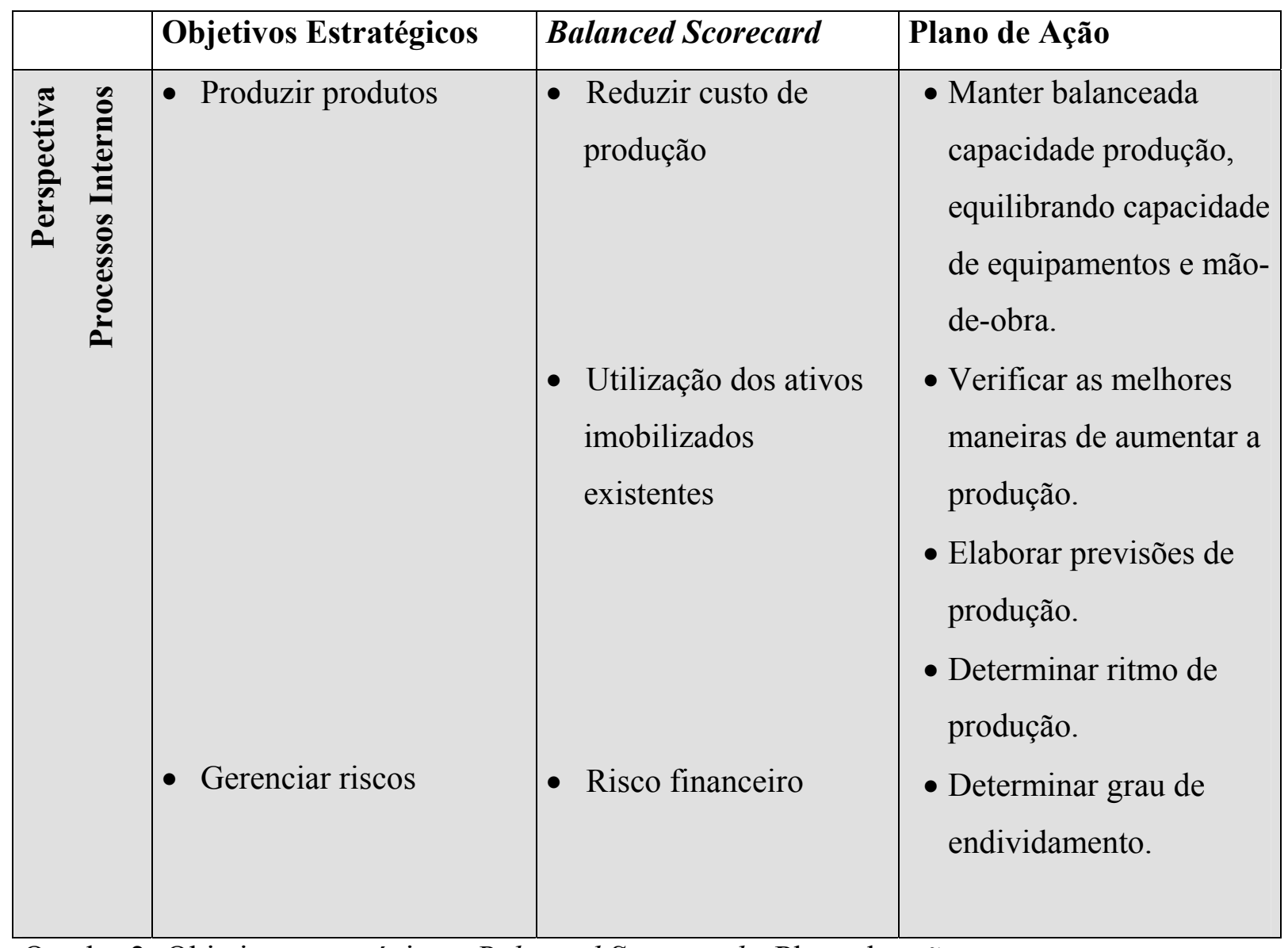

Quadro 2- Objetivos estratégicos, Balanced Scorecard e Plano de ação. 
Fonte: (Adaptado de KAPLAN e NORTON, 2004).

O equilíbrio da capacidade de equipamentos e mão-de-obra, o ritmo e a previsão de produção irão indicar a necessidade de investimentos na capacidade de produção.

\section{ATUALIZAÇÕES NO GI-LOGÍSTICA}

Entende-se que o Balanced Scorecard cumpriu o papel de balizador às atualizações do jogo de empresas GI-Logística, visto que esclarece elementos estratégicos na tomada de decisão. Elementos que, conforme sugere Ishikawa (2004), receberão um "balanceamento", com o intuito de diminuir sua complexidade no processamento no jogo. Portanto, dois itens receberam especial atenção, a Administração Financeira e as Modalidades de Empréstimos.

A Administração Financeira recebeu alterações operacionais e mais um tópico no manual, denominado Investimento na Capacidade de Produção, Manual do Jogador, p.38 (KOPITTKE, 2000). Anteriormente, o leque de decisão sobre a capacidade produtiva apresentava-se limitado: uma empresa poderia investir 50.000 e outra, por exemplo, 55.000. Para efeitos práticos, as duas decisões anteriores são equivalentes, mas devido à percepção ainda precária que os jogadores têm no início do jogo, eles poderão gastar muito tempo discutindo se o valor do investimento será de 50.000, 55.000 ou um outro valor intermediário. Após as modificações, o investimento na capacidade produtiva é balizado. Os participantes são informados de forma clara quais opções possuem para manter, aumentar ou deixar depreciar a capacidade produtiva do seu parque fabril. A seguir, apresenta-se o modelo proposto:

\section{Investimento na Capacidade de Produção}

Os investimentos para manter ou aumentar a capacidade de produção do parque fabril da empresa serão definidos pelas decisões de investimento no imobilizado. Existem quatro opções de investimentos, além da possibilidade de não investir, onde, conseqüentemente, a empresa diminuirá a capacidade produtiva de suas máquinas. As opções de investimento são:

- opção 0 : nenhum investimento será realizado, ou seja, esta opção deixa os equipamentos depreciarem;

- opção 1 : o investimento será igual a depreciação, mantendo a capacidade produtiva. Nesta opção, o investimento poderá ser financiado a curto prazo; 
- opção 2 : o investimento será de $50.000 \mathrm{UM}$, aumentando a capacidade produtiva. Nesta opção, o investimento poderá ser financiado a longo prazo, pelo SAC (Sistema de Amortização Constantes), com taxa de juros do BC;

- opção 3 : o investimento será de 200.000 UM, aumentando a capacidade produtiva. Esta opção conta com uma linha de crédito especial, onde a taxa de juros é de $3 \%$ ao período, com 6 períodos de carência, mais 6 períodos de amortização (SAC).

- opção 4 : o investimento será de 400.000 UM, aumentando a capacidade produtiva. Assim como a opção 3, este investimento poderá utilizar a linha de crédito especial.

Quanto às opções apresentadas, observa-se que essas já foram aplicadas e testadas em turmas de graduação e pós-graduação, tendo sido validadas.

A outra alteração relevante, fruto desta pesquisa, refere-se às Modalidades de Empréstimos, que são apresentadas no tópico do manual do jogador "O Mundo GI-Logística Micro”. Este item recebeu modificações na forma operacional e no texto que o apresenta, no Manual do Jogador, p.17 (KOPITTKE, 2000). As modalidades de empréstimos oferecidas aos empresários virtuais do jogo de empresas, anteriormente, eram de prazo curto, médio e longo. A modalidade de curto prazo destinava-se a empréstimo para capital de giro e deveria ser devolvido no período seguinte; a modalidade médio prazo também se destinava a empréstimos de giro, porém pagos por meio do Sistema de Amortização Constante, em três vezes. Já a modalidade longo prazo era destinada aos investimentos na capacidade produtiva, com carência de quatro períodos e pagamento pelo SAC, em cinco parcelas. Empréstimos de médio e longo prazo possuíam taxas de juros especiais. Atualmente apresentam-se três modalidades de pagamento de empréstimos, que são:

- Capital de Giro: Também concedido pelo BICASA, com propósito de satisfazer necessidades de capital de giro. Nesta modalidade, o montante será pago pelo SAC (Sistema de Amortizações Constantes), em três parcelas sem carência.

- Longo Prazo: Concedido apenas pelo BADEL, destina-se a financiar investimentos em capacidade produtiva. O montante será pago pelo SAC em cinco parcelas, com carência de quatro períodos. Neste caso, a taxa de juros será igual à taxa do BC. Normalmente, o BADEL financia até $90 \%$ do montante total, mas o cenário pode se alterar.

- Especial: Assim como no longo prazo, esta modalidade de empréstimo é concedida apenas pelo BADEL. Destina-se a financiar investimentos em capacidade produtiva e conta com uma taxa de juros é de 3\% ao período. Sua carência é de 6 períodos, mais 6 períodos de amortização (SAC). 


\section{CONSIDERAÇÕES FINAIS}

O investimento na capacidade de produção é um fator estratégico no jogo de empresas e tem influência significativa nos objetivos analisados nesta perspectiva, pois para a empresa manter-se competitiva deve ocorrer o balanceamento na produção.

O Balanced Scorecard proporciona uma visão clara da empresa como um sistema integrado, uma visão holística e a compreensão da relação de causa e efeito entre as diversas estratégias. Desta maneira, o envolvimento dos decisores em torno da estratégia, torna-se um fator crítico de sucesso, conduzindo a um desempenho superior ao dos concorrentes.

Sugere-se como seqüência desse trabalho, a avaliação do jogo de empresas GILogística, sob outros aspectos da perspectiva dos processos internos, e de outras perspectivas do Balanced Scorecard.

\section{REFERÊNCIAS}

ALBUQUERQUE, F. D. Metodologia de decisão multicriterial e coletiva para investimentos em situações de risco. Dissertação de Mestrado em Engenharia de Produção/UFSC, Florianópolis: UFSC, 1987.

DETTMER, Armando Luiz. Concebendo um laboratório de engenharia de produção utilizando um jogo de empresas. Tese de doutorado em Engenharia de Produção/UFSC. Florianópolis: UFSC, 2001.

ISHIKAWA, Gerson. A introdução da Gestão Logística em Jogos de Empresas Aplicação das Proposições ao Sistema GI-Logística. Disc. Gestão de Negócios com Aplicação de Jogos de Empresas, Pós Graduação em Engenharia de Produção/UFSC, Florianópolis: UFSC, 2004.

KAPLAN, Robert e NORTON, David. Mapas Estratégicos - Balanced Scorecard: convertendo ativos intangíveis em resultados tangíveis. Rio de Janeiro: Elsevier, 2004.

KAPLAN, Robert e NORTON, David. Organização orientada para a estratégia. Rio de Janeiro: Campus, 2001.

KAPLAN, Robert e NORTON, David. A estratégia em ação. Balanced Scorecard. Rio de Janeiro: Campus, 1987.

KOPITTKE, Bruno Hartmut et alli. Jogo de empresas GI-EPS: manual do jogador. Apostila editada no Departamento de Engenharia de Produção e Sistemas da Universidade Federal de Santa Catarina, Florianópolis: UFSC, 2000. 
SILUK, Julio C.M. Avaliação do Jogo de Empresas GI-Logística sob a Perspectiva dos Processos Internos do Balanced Scorecard. Disc. Gestão de Negócios com Aplicação de Jogos de Empresas, Pós Graduação em Engenharia de Produção/UFSC, Florianópolis: UFSC, 2004. 